\title{
Metamorphic evolution of subducting sediments detected by sparse-modelling
}

Kenta Yoshida $^{1 *}$, TAtsu Kuwatani ${ }^{12}$, Kenta UeKI $^{1}$, RYOSUKE OYANAGI ${ }^{1}$, SHOTARO AKAHO ${ }^{3}$

${ }^{1}$ Research Institute for Marine Geodynamics, Japan Agency for Marine-earth Science and Technology (JAMSTEC), Kanagawa 237-0061, Japan *yoshida_ken@jamstec.go.jp

${ }^{2}$ PRESTO, Japan Science and Technology Agency, Saitama 332-0012, Japan

${ }^{3}$ National Institute of Advanced Industrial Science and Technology, Ibaraki 305-8560, Japan

The progressive evolution of subducting rocks under intermediate high- $P / T$ type metamorphism was modelled using a combination of thermodynamic calculations and mass-transfer calculations. The datadriven isocon analysis (Sparse Isocon method) [1] was applied to the major component dataset of a series of metapelites collected from the Sanbagawa metamorphic belt in southwest Japan. This allowed quantitative modelling of the mass gain/loss during progressive metamorphism. The isocon analysis indicated a total mass loss of 6 mass $\%$ during the progressive metamorphism, involving the loss of $\mathrm{Na}$ and $\mathrm{Si}$ and the gain of divalent cations with $\mathrm{Al}$ as the least-mobile element. Thermodynamic calculation shows that $\mathrm{Na}$ and Si show higher mobility than other elements under the equilibrium conditions of the studied rocks. These calculations indicate that the evolutionary change in the Sanbagawa metapelites is characterized not only by mass loss as a result of the high-temperature fluid flushing, but also through the addition of mafic components. These mafic components may have originated from the material transfer of the ultramafic bodies, while the loss of $\mathrm{Na}$ and $\mathrm{Si}$ is indicative of the high-temperature fluid flushing under the shallow part (15-30 km) of the subduction zone.

1 doi:10.1016/j.chemgeo.2019.119345 